\title{
ELEVATED STRATIFIED LAYERS OBSERVED DURING VTMX
}

\section{By}

R. L. Coulter, M. S. Pekour, and

T. J. Martin

Environmental Research Division

Argonne National Laboratory

Argonne, IL 60439-4843

$11^{\text {th }}$ International Symposium on Acoustic

Remote Sensing

24-28 June 2002, Rome, Italy

Work at Argonne National Laboratory was supported by the U.S. Department of Energy, Office of Science, Office of Biological and

Environmental Research, Environmental

Sciences Division, under contract W-31-109Eng-38.

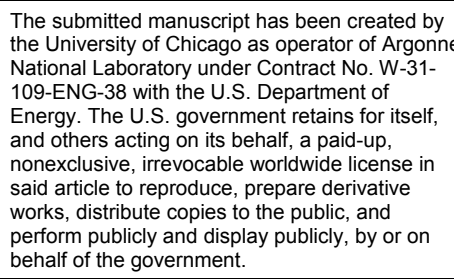

\section{ELEVATED STABLE LAYERS OBSERVED DURING VTMX}

R. L. Coulter, M. S. Pekour and T. J. Martin 


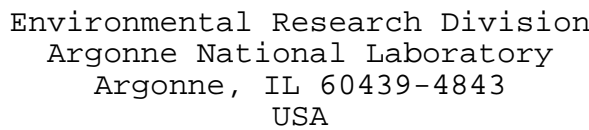

\begin{abstract}
A suite of instrumentation including a minisodar, a low-frequency, single-axis sodar, a wind profiling radar and a tethersonde was used during the Vertical Transport and Mixing field study in Salt Lake City, UT, USA, to study the evolution and dynamics of stratified layers that commonly develop during nighttime. The month-long field study provided ten nights with good conditions for tethersonde flights. The real-time sodar display was used to place the tethersonde within and near the stratified layers and to make multiple transects, while atmospheric temperature, moisture, wind speed and wind direction were measured. Not surprisingly, the existence of layers with enhanced acoustic scattering correlated well with regions of potential temperature inversions; however, because wind speeds were invariably low, the Richardson number was rarely less than 0.25 . The possible role of moisture in the dynamics of elevated stable layer is discussed.
\end{abstract}

\section{INTRODUCTION}

Stratification of the atmosphere within and above the nocturnal boundary layer (NBL) is a persistent feature, particularly above basins in mountainous terrain where cold air drainage establishes a strongly stable environment immediately above the surface. Furthermore, drainage from multiple locations mixes poorly above the surface-based inversion in calm conditions. The result is a complex structure within the transition layer (TL), that portion of the atmosphere between the strongly stable NBL and the free atmosphere above the remnants of the previous day's mixed layer. Mountain effects such as internal gravity waves further complicate the picture. Evidence for this stratification is particularly evident on time-height cross sections of signal returns from active remote sensors such as lidars, radars, and sodars, most often as elevated regions of enhanced signal return that maintain a cohesive structure for extended periods of time. During daytime, the capping inversion at the top of the well mixed-layer is a particularly well-defined example of such an elevated stable layer (ESL); in fact, the remnant of this ESL often continues through the nighttime. The definition of the ESLs within the TL typically is considerably less clear than the definition of the daytime capping inversion. However, because the turbulence levels aloft during nighttime are often quite weak in light-wind conditions, these regions potentially play an important role in the nocturnal transport and diffusion of scalar quantities above urban areas located in mountainous regions.

The Vertical Transport and Mixing (VTMX) (Doran, et al., 2002) field study in the Salt Lake City area during October 2000 provided an opportunity to study ESLs in some detail. We used a combination of radar wind profiler, high-frequency sodar (minisodar), low-frequency, vertical-axis sodar (maxisodar), and tethered balloon system to monitor and take measurements within a number of ESLs during the study period. The equipment was located at the Old Mill Golf Course, southeast of the urban area along the eastern edge of the basin, within $500 \mathrm{~m}$ of the rapidly rising western edge of the Wasatch Mountains. Because this site was between the outflow from Parley's Canyon to the north and Big Cottonwood Canyon to the south, the competing flows from the canyons often cancelled one another. As a result, light winds prevailed on almost all study nights. This enabled tethersonde flights (notoriously difficult to handle in winds approaching $10 \mathrm{~m} \mathrm{~s}^{-1}$ ) to often reach the maximum allowable height of $500 \mathrm{~m}$. Moreover, positioning of the balloon almost vertically above its launch point usually made it easily visible on sodar and radar vertical time sections; thus, it was possible to coordinate layer definition with the measurements of temperature and moisture within those layers.

\section{PROCEDURE}

Figure 1 shows vertical time sections from the profiler and maxisodar for one study day. The ESLs are defined by the coherent darker regions. The time and space resolution of the profiler (60-m range gates; 3 min period) is clearly much coarser than that of the sodar (15-m range gates; 9-sec period), and the profiler's minimum usable height $(150 \mathrm{~m})$ makes its layer definition difficult. In addition, the layers defined by the two instruments are not necessarily 


\section{Oct 2000 (VTMX-omgc)}
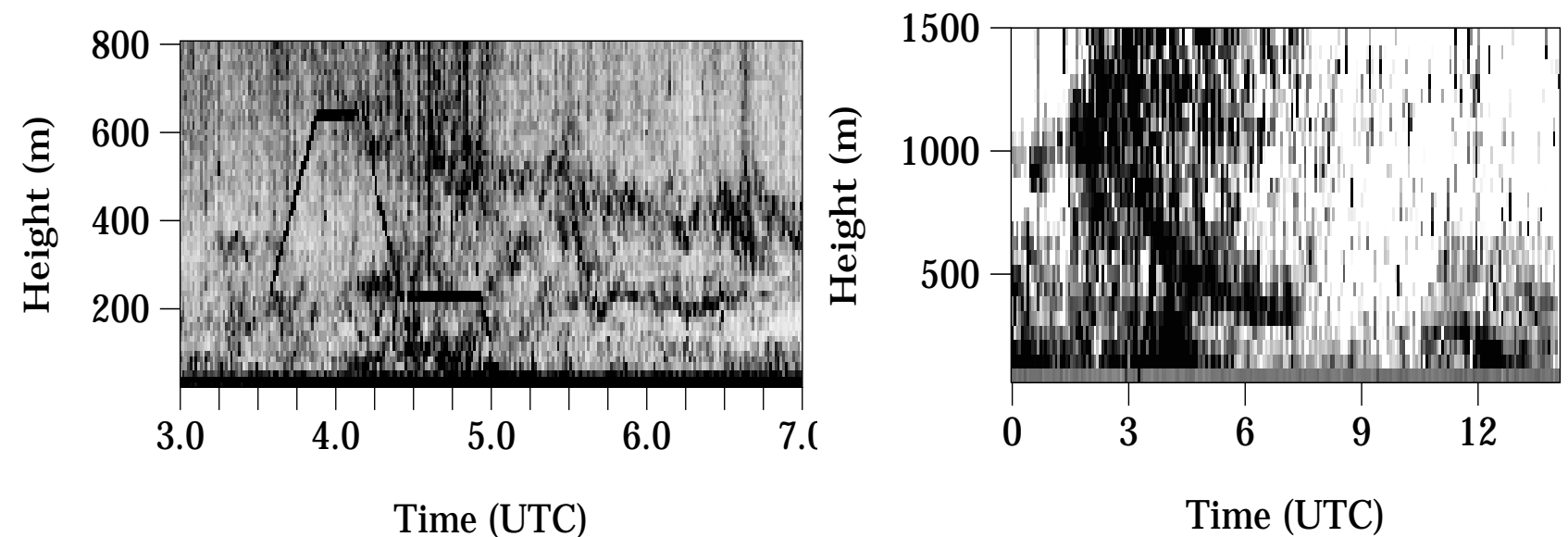

Figure 1. Vertical time sections of maxisodar (left) and 915-MHz radar wind profiler (right) signal amplitudes during nighttime of 8 October 2000 along the eastern edge of the Salt Lake City basin. Increased signal corresponds to increased darkness. Note the effects of different space and time resolutions on the layer definition.

the same, because the profiler responds primarily to moisture fluctuations, while the sodar is sensitive almost entirely to temperature fluctuations. For these reasons and because the sodar returns could be monitored in real time, the maxisodar data were used to vector the tethersonde to "penetrate" ESLs. The tethersonde was usually visible on the vertical time section of the maxisodar when its height exceeded 100 $\mathrm{m}$ (because the two devices were separated by $50 \mathrm{~m}$ ). The tethersonde was most often used to profile through layers of interest (see Results below); however, it was occasionally positioned at a constant height within an ESL.

Although the light-wind conditions made it possible to reach reasonable altitudes, they often resulted in very poor evaluation of wind direction (although wind speed was generally acceptable) because of the balloon's response to changing wind direction. In light conditions, with variable wind directions, the balloon angular momentum often causes it to rotate through and beyond the true wind direction. For that reason, the wind directions reported are assumed to be unreliable. More importantly, reliable calculations of Richardson number were not possible without accurate values of the $\mathrm{u}$ and $\mathrm{v}$ wind components.

Data from the tethersonde package consisted of atmospheric pressure (height), dry- and wet-bulb temperatures, wind speed, and wind direction (not used). Signal amplitude was the principal measurement of interest from the sodar and radar. Vertical velocity (w) and standard deviation of vertical velocity $\left(\sigma_{\mathrm{w}}\right)$ were also available from the sodar; however, when vertical velocity magnitudes are small, values of $\sigma_{w}$ are unreliable, particularly with low-frequency systems
(Coulter and Martin, 1986). Radar wind components were obtained; however, they were not used for this study because the sample rate $\left(0.333 \mathrm{~min}^{-1}\right)$ was too small to be useful.

\section{DATA ANALYSIS}

Forty-four tethered balloon flights were carried out on nine different intensive study nights during VTMX. From these flights more than 320 "penetrations" of ESLs occurred. Of these, 177 were used in the following data analysis. Reasons for discarding data included bad pressure or wet-bulb data from the tethersonde package, poor layer discrimination, and unacceptable tethersonde motion during measurement (tethered-line problems and too-rapid vertical movement, for example).

The ESLs were defined by using a graphical interface to view increased signal regions of the maxisodar and radar vertical time. Some of the defined layers are coincident, indicating the presence of both temperature and moisture fluctuations, while others are not. We cannot determine at this point whether the lack of coincidence of certain layers is a result of temperature/moisture fluctuations below the detection limit of the sodar/radar (due to different volume averaging effects, for example) or indicates lack of a true relationship. The better time and height resolution of the maxisodar results in more definition of layer movement, especially near the surface.

The location of the true intersection of the sonde movement with each layer was complicated by the fact that the scales of the temperature and moisture differences varied from case to case and were often 
less than one range gate; the maximum signal nearest the graphically chosen layer location was used. (The graphical depiction of the layer generally defined only the maximum signal region, whose depth was often several range gates because of volume-averaging effects.)

Figure. 2 is an example of a single layer location and two of the temperature and moisture profiles associated with it. The defined layers often changed positions relatively quickly with time; thus, the moisture and temperature profiles are plotted with their intersection at the appropriate time for comparison with the defined layer. The ESL is characterized by an increased temperature gradient immediately above a less stable, but often not adiabatic, portion, while the moisture decreases noticeably at and above the ESL and is almost well mixed immediately below. This fits the picture of shear-based mixing at the base of the temperature inversion, from which temperature fluctuations and a resultant increase in sodar signal strength develop. With increasing height (into the inversion), the mixing decreases. At the same time, the moisture is relatively constant immediately below the middle of the ESL, due to the same small-scale shear and decreases above that point. We note, however, that as the layer changes (descends in this case), the temperature and moisture profiles also change, with the temperature profile becoming more stable above the layer but remaining relatively unstable below.

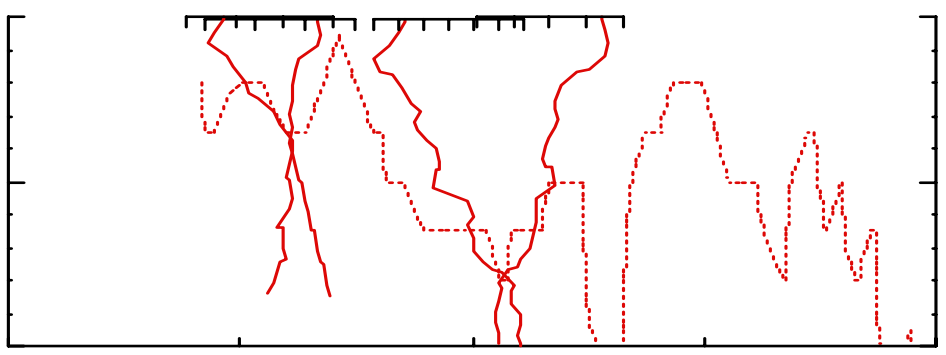

Figure 2. Temperature (thick solid line) and mixing ratio (thin solid line) profiles from a tethersonde near a single defined layer. In this case the layer (dotted line) is determined as the maximum in relative sodar signal nearest the graphically chosen maximum (which might not be a true maximum). The "common" time occurs at the intersection of temperature and mixing ratio profiles. Ticks divisions are $0.1 \mathrm{~g} \mathrm{~kg}-1$ or $0.5 \mathrm{~K}$ for $\mathrm{R}$ and Q per $100 \mathrm{~m}$.
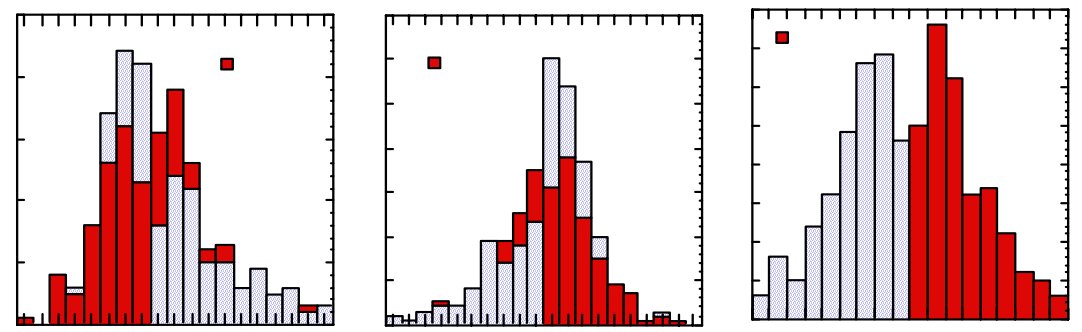

Figure 3. Stacked histogram of gradients of potential temperature (left), mixing ratio (center), and sodar signal strength (right) at the middle of a layer defined from the relative maximum in sodar vertical time sections. Upper/lower half values refer to portion above/below the middle of the layer.

Meanwhile the inflection point in the moisture profile apparently descends with the layer. However, this simple scenario is not always the case. The mixing ratio $(\mathrm{R})$ profile generally decreased and the potential temperature $(\Theta)$ increased with height through the transition region (Table 1). Values of potential temperature and mixing ratio differences were determined for each layer penetration by the tethersonde. These values were defined by the estimated scale of the temperature difference, as well as the gradient of sodar signal.

\section{RESULTS}

The mean profiles of $\Theta$ and $\mathrm{R}$ (increased/decreased) at $\left(1.2 \mathrm{~K}[100 \mathrm{~m}]^{-1} / 0.14 \mathrm{~g} \mathrm{~kg}^{1}[100]^{-1}\right)$ respectively, in the transition region (Table 1). Within the NBL immediately above the surface, the $\Theta$ profile generally increased considerably more rapidly as the surface 
cooled during nighttime. Within the ESLs, the difference between the most probable temperature gradient in the upper and lower halves of the layers is approximately $1 \mathrm{~K}\left(100 \mathrm{~m}^{-1}\right.$ (Fig. 3). The mixing ratio difference is a less well-defined $0.2 \mathrm{~g} \mathrm{~kg}^{-1}(100 \mathrm{~m})^{-1}$;

The mean distance over which the temperature and moisture inflections occur (defined as twice the distance spanning the maximum temperature gradient) is $14 \mathrm{~m}$, with standard deviation of $10 \mathrm{~m}$. In contrast, the mean layer thickness (defined by sodar vertical time sections) is $60 \mathrm{~m}$. The minimum distance of the temperature inflections is normally near $6 \mathrm{~m}$ (determined by the sonde sample rate $\left[0.1 \mathrm{~s}^{-1}\right]$ and balloon rise rate $\left.\left[0.3 \mathrm{~ms}^{-1}\right]\right)$; thus, the true mean is likely less. Similarly, the sodar range gate of $15 \mathrm{~m}$ predicates a minimum defined layer size of nearly 30$45 \mathrm{~m}$. Table 1 illustrates the increased $\Theta$ and decreased $\mathrm{R}$ values in the upper half of the layers relative to background. Multiple $\Theta$ and $R$ values obtained from successive penetrations of the same layer provide a "Lagrangian" gradient as the layers change height. These values, also given in Table 1,

\begin{tabular}{|l|l|l|l|l|l|l|l|l|l|}
\hline Date & 07 & 08 & 09 & 15 & 17 & 18 & 20 & 26 & All \\
\hline Tbck & .83 & .85 & 1.2 & .69 & 1.1 & 1.2 & 1.6 & .8 & 1.2 \\
\hline Rbck & -.3 & -.1 & -.1 & -.1 & -.1 & -.2 & -.2 & -.0 & -.1 \\
\hline Tup & 2.1 & 1.3 & 3.2 & 2.4 & 3.0 & 3.3 & 4.0 & 2.8 & 3.2 \\
\hline Tdn & .26 & .88 & 1.5 & .3 & 1.2 & 1.2 & 1.2 & .47 & 1.0 \\
\hline Rup & -.6 & -.4 & -.5 & -.5 & -.3 & -.8 & -.5 & -.2 & -.5 \\
\hline Rdn & .04 & -.1 & .09 & -.0 & .2 & -.0 & .00 & .1 & .03 \\
\hline T1 & .86 & .75 & 2.0 & .42 & 1.1 & 1.2 & 1.7 & .65 & 1.3 \\
\hline Rl & -.6 & -.5 & -.3 & -.2 & -.1 & -.2 & -.2 & -.2 & -.2 \\
\hline Tlasc & -.4 & -.3 & 2.0 & 0.0 & .8 & 1.2 & .9 & -.1 & .86 \\
\hline Tldes & 1.3 & 1.8 & 2.2 & .85 & 1.5 & 1.3 & 2.7 & 4.2 & 1.9 \\
\hline Rlasc & -1. & -.7 & -.3 & -.5 & -.2 & -.4 & -.3 & -.2 & -.3 \\
\hline Rldes & -.4 & -.3 & -.6 & .1 & .17 & -.1 & -.1 & -.3 & -.1 \\
\hline
\end{tabular}

Table 1. Nightly mean values of gradients of background potential temperature (Tbck) and mixing ratio (Rbck), gradients of $\Theta$ in the upper (Tup) and lower (Tdn) halves of the layers, and gradients of $\mathrm{R}$ in the upper(Rup) and lower (Rdn) halves. Also shown are the gradients within the layers (l) and as they ascend (asc) or descend (des). Gradient units are $\mathrm{K}$ or $\mathrm{g}$ $\mathrm{kg}^{-1}(100 \mathrm{~m})^{-1}$.

strongly indicate that the potential temperature gradient is consistently smaller than background $(0.31$ $\mathrm{K}[100 \mathrm{~m}]^{-1}$ less stable in the mean) within rising layers and larger than background $\left(0.72 \mathrm{~K}[100 \mathrm{~m}]^{-1}\right)$ more stable in the mean) within descending layers. The mixing ratio gradient within rising layers is more negative than the background $\left(0.28 \mathrm{~g} \mathrm{~kg}^{-1}[100]^{-1}\right)$ and less negative overall $\left(0.064 \mathrm{~g} \mathrm{~kg}^{-1}[100 \mathrm{~m}]^{-1}\right)$ within descending layers; however, the mixing ratio differences are not as consistent as the potential temperature differences. (On half of the nights the mixing ratio gradient from within descending layers even so, the distribution (Fig. 3) shows a marked shift toward lower values (decreasing moisture) in the upper portion of the layers.

was more negative than background.) Thus the layers apparently cool relative to the background regardless of their direction of movement. Excess radiative cooling within the layers due to

excess moisture relative to the background may be one of the mechanisms for this cooling.

Unfortunately wind direction values from the tethersonde are unreliable. Any relationship between layer strength as defined by sodar or radar signal strength and inversion strength requires knowledge of the local Richardson number. Use of $\sigma_{\mathrm{w}}$ estimates from the sodar might be possible; however, as noted above, they might be unreliable as well.

A "generic" picture of the $\Theta$ and R profiles within the transition layer above complex terrain thus appears as a series of step-like regions within which $\Theta$ increases as $\mathrm{R}$ decreases and below which the moisture approaches a well mixed state and the temperature profile is less stable, sometimes becoming adiabatic. The number, location, stability, and movement of the layers are important to vertical transport.

\section{ACKNOWLEDGEMENT}

We would like to thank the personnel at the Old Mill Golf Course, particularly Mr. Curt Hirase, for the use of their site and their kind support of, and interest in, this field study. This work was supported by the U. S. Department of Energy, Office of Science, under the auspices of the Atmospheric Science Program of the Office of Biological and Environmental Research, Environmental Sciences Division, under contract W31-109-Eng-38 as part of the Environmental Measurements Program.

\section{REFERENCES}

Coulter, R. L. and T. J. Martin, 1986. Results from a high power, high frequency sodar, Atmospheric Research 20 \# (2-4), pp. 257270.

Doran, J. C., J. D. Fast, and J. Horel, 2002. The VTMX 2000 Campaign, Bulletin of the American Meteor ological Society, 
